\title{
ANALISA VISUALISASI DATA AKADEMIK MENGGUNAKAN TABLEAU BIG DATA
}

\author{
Dedy Hartama \\ Program Studi Teknik Informatika, STIKOM Tunas Bangsa Pematangsiantar. \\ Jln. Sudirman Blok A No 1,2 dan 3 Pematangsiantar 21111 - Indonesia \\ dedyhartama@yahoo.com
}

\begin{abstract}
This research explains the benefits of data analysis by visualizing Big data in performing optimization in the academic management environment. The data used is academic information system database that related with student status. In this study the authors use Tableau tools to perform data analysis based on the number of students worksheet, student status, student name table and generate student dashboard data. The results of the analysis obtained by using visualization in bemtuk management graph is very fast and optimize data processing so mengatahui the development of academic database situation.
\end{abstract}

Keywords: Visualization, Big data, Tableau analysis, worksheet, dashboard

\begin{abstract}
Abstrak
Penelitian ini menjelaskan manfaat analisis data secara visualisasi Big data dalam melakukan optimalisasi di lingkungan manajemen akademik. Data yang digunakan adalah database sistem informasi akademik yang berhubungan dengan status mahasiswa. Dalam peneltian ini penulis menggunakan tools Tableau untuk melakukan analisis data berdasarkan worksheet jumlah mahasiswa, status mahasiswa, tabel nama mahasiswa dan menghasilkan dashboard data mahasiswa. Hasil analisis yang diperoleh dengan menggunakan visualisasi dalam bemtuk grafik manajemen sangat cepat dan mengoptimalkan pengolahan data sehingga mengatahui perkembangan keadaan database akademik.
\end{abstract}

Keywords: Visualisasi, Big data, Tableau analisis, worksheet, dashboard

\section{PENDAHULUAN}

Big data merupakan volume data yang besar volume dalam kisaran exabytes. Volume tersebut melebihi kapasitas penyimpanan sistem on-line saat ini dan proses sistem pengolahan data. Data, informasi, dan pengetahuan yang diciptakan dan dikumpulkan pada tingkat yang cepat mendekati kisaran exabyte pertahun. Tapi, penciptaan data dan agregasi mempercepat dan akan pendekatan kisaran zettabyte pertahun dalam beberapa tahun. Volume adalah hanya satu aspek dari data yang besar; atribut lain adalah berbagai, kecepatan, nilai dan kompleksitas. Penyimpanan dan data transportasi adalah masalah teknologi, yang tampaknya akan dipecahkan dalam waktu dekat, tapi mewakili tantangan jangka panjang yang memerlukan penelitian dan paradigma baru [1].

Defenisi Big data adalah sebagai jumlah data besar hanya di luar kemampuan teknologi untuk menyimpan, mengelola dan memproses secara efisien. Sesedikit 5 tahun yang lalu, kami yang hanya memikirkan puluhan hingga ratusan gigabyte penyimpanan untuk komputer pribadi kita. Hari ini, kami berpikir dalam puluhan hingga ratusan terabyte. Dengan demikian, data yang besar adalah target yang bergerak. Dengan kata lain, itu adalah jumlah data yang hanya di luar pemahaman kami segera, misalnya, kita harus bekerja keras untuk menyimpannya, 
mengaksesnya, mengelola dan memproses [1]. Analisis Big data dapat dibedakan dari arsitektur tradisional data processing di sejumlah dimensi:

1. Kecepatan pengambilan yang sangat penting bagi para pengambil keputusan

2. Pengolahan kompleksitas karena ini memudahkan keputusan proses pembuatan

3. Transaksi data volume yang sangat besar

4. Data struktur data dapat terstruktur dan tidak terstruktur

5. Fleksibilitas terdiri dalam jumlah analisis yang dapat dilakukan pada pengolahan/analisis [2]

Analisis Big data inisiatif harus proyek bersama melibatkan TI dan bisnis. IT harus bertanggung jawab untuk menyebarkan alat analisis data tepat besar dan menerapkan praktek-praktek pengelolaan data suara. Kedua kelompok harus memahami bahwa keberhasilan akan diukur oleh nilai tambah oleh perbaikan bisnis yang disebabkan oleh inisiatif [3]. Untuk membuat setiap keputusan yang diinginkan ada adalah kebutuhan untuk membawa hasil penemuan pengetahuan untuk proses bisnis dan di jalan waktu yang sama dampak di berbagai dashboard, laporan dan analisis pengecualian yang sedang dipantau. Pengetahuan baru ditemukan melalui analisis mungkin juga memiliki bantalan pada business strategy, CRM strategi dan strategi finansial yang maju [3] Lihat gambar 1 berikut

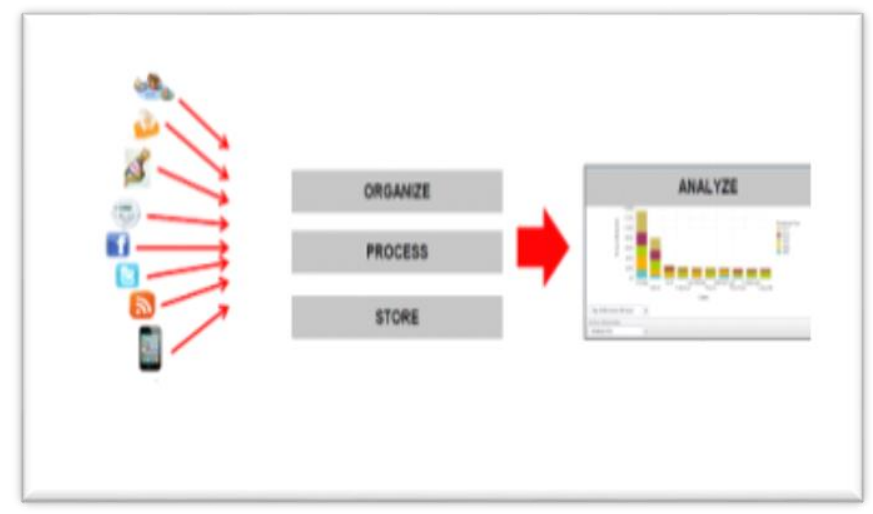

Gambar 1. Manajemen Big data [3]

Dengan munculnya "Big data", visualisasi informasi yang muncul sebagai daerah yang tak seorang pun dapat mengabaikan. Lembaga yang menemukan bahwa pemegang saham utama ingin diberikan dengan metrik ketika diminta untuk membuat keputusan [4].

Tableau digunakan sebagai alat visualisasi untuk lebih baik mengelola jumlah data yang besar secara model grafik. Memanfaatkan visualisasi data ini efektif karena: Visualisasi grafik dari representasi data jauh lebih kuat daripada tampilan dalam bentuk angka. Sementara tabel memerlukan kita untuk membaca dan mempertimbangkan makna dan hubungan setiap nilai individu yang disajikan, visualisasi mengizinkan untuk memproses banyak nilai-nilai secara bersamaan. Lebih lanjut, manusia dapat lebih efisien dan efektif proses grafik dari tabel numerik teks. Dengan demikian, visualisasi memungkinkan analisis untuk mengenali tren, tempat pola, dan mengidentifikasi dengan cepat dan optimal [5]. 


\section{METODOLOGI PENELITIAN}

\subsection{Permasalahan Big data}

Big data menjadi tak terlihat seperti "tambang emas" nilai potensial yang dikandungnya. Dengan akumulasi dan pertumbuhan produksi, operasi, manajemen, pemantauan, penjualan, Layanan pelanggan, dan jenis lain dari data, serta peningkatan jumlah pengguna, menganalisis korelasi pola dan tren dari jumlah besar data memungkinkan untuk mencapai pengelolaan yang efisien, presisi pemasaran. Ini dapat menjadi kunci untuk membuka "tambang emas." tetapi, infrastruktur TI secara tradisional dan metode untuk pengelolaan data dan analisis tidak dapat beradaptasi dengan pertumbuhan cepat data besar [6]. Kita merangkum masalah besar data ke dalam tujuh kategori dalam tabel 1

Tabel 1. Permasalahan di Big data [6]

\begin{tabular}{|l|l|}
\hline Klasifikasi masalah Big data & Keterangan \\
\hline kecepatan & $\begin{array}{l}\text { Masalah impor dan ekspor } \\
\text { Masalah Analisis dan Statistik } \\
\text { Masalah Query } \\
\text { Masalah Real time }\end{array}$ \\
\hline Jenis dan Struktur & $\begin{array}{l}\text { Masalah multisource } \\
\text { Masalah heterogenitas } \\
\text { Masalah infrastruktur sistem }\end{array}$ \\
\hline Volume dan fleksibilitas & $\begin{array}{l}\text { Masalah skala linier } \\
\text { Masalah penjadwalan secara Dinamis }\end{array}$ \\
\hline Biaya & $\begin{array}{l}\text { Biaya perubahannya antara mainframe dan } \\
\text { server PC } \\
\text { Biaya kontrol sistem yang asli }\end{array}$ \\
\hline Nilai Data Mining & $\begin{array}{l}\text { Analisis data mining } \\
\text { Manfaat sebenarnya dari data mining. } \\
\text { Terstruktur dan non terstuktur }\end{array}$ \\
\hline Keamanan dan privasi & $\begin{array}{l}\text { Keamanan Data } \\
\text { Privasi }\end{array}$ \\
\hline Konektivitas dan berbagi data & $\begin{array}{l}\text { Data standar dan interface } \\
\text { Protokol untuk berbagi } \\
\text { Akses Kontrol }\end{array}$ \\
\hline
\end{tabular}

\subsection{Teknologi Big data}

Big data tidak hanya memberikan keuntungan tetapi juga sebuah tantangan. Pemrosesan data tradisional tidak mampu memenuhi permintaan pemrosesan data real-time yang sangat besar; kita membutuhkan generasi baru teknologi informasi untuk menangani permasalahan Big data. Tabel 2 mengklasifikasikan teknologi Big data menjadi lima kategori [6]. 
Tabel 2. Klasifikasi dari Teknologi Big data [6]

\begin{tabular}{|l|l|}
\hline Klasifikasi Teknologi Big data & \multicolumn{1}{|c|}{ Teknologi Big data dan Alat } \\
\hline Dukungan infra struktur & Platform Komputasi awan \\
& Penyimpanan Cloud \\
& Teknologi Virtualisasi \\
& Teknologi Network \\
& Pengawasan sumber daya teknologi \\
\hline Akuisis data & Data Bus \\
& ETL Tools \\
\hline Penyimpanan data & Sistem Distribusi File \\
& Database Relational \\
& Teknologi NoSQL \\
& Integrasi Relasi database dan Non \\
& Relasional database \\
& Database di memori \\
\hline Perhitungan data & Data Query, Statisktik, dan analisa data \\
& Data Mining dan Prediksi \\
& Grafik Analisis \\
& BI (Bisnis Inteligence) \\
\hline Tampilan dan Interaksi & Grafik dan Laporan \\
& Tampilan Visualisasi \\
\hline
\end{tabular}

\subsection{Evolusi Pemrosesan dari Big data}

Tantangan utama yang ditimbulkan oleh masalah Big data adalah kemampuan untuk memproses aliran data yang ditandai dengan 3Vs variety, velocity, dan volume. Sumber Big data menghubungkan database terstruktur secara tradisional untuk memasukkan email, sensor, kamera video, media sosial, dan perangkat seluler (teks, video, dan audio) [7].

Pengolahan frameworks Big data juga harus berurusan dengan dataflows heterogen (misalnya, statis, streaming, dan transaksi), pengolahan data heterogen semantik (pengolahan batch di Hadoop, pengolahan aliran data secara realtime di mesin dan pengolahan transaksi di MySQL dan Cassandra). Tipe data heterogen (misalnya data terstruktur dari Twitter, data terstruktur dari tradisional SQL database dan data gambar dari kamera video) diatur dengan memvariasikan data volume, kecepatan data, dan jenis permintaan [7].

Untuk menjamin kinerja, penjadwalan kebutuhan platform untuk dapat memprediksi tuntutan dan perilaku kerangka yang mendasari sehingga mereka dapat cerdas mendistribusi kan dan memprioritaskan beban kerja. Lebih jauh, hal ini tidak jelas bagaimana prioritas tersebut dapat dilestarikan di beberapa kerangka karena dataflows diproses di seluruh platform yang didistribusikan [7]

\section{HASIL DAN PEMBAHASAN}

Menurut [8] , Big data merupakan istilah yang berlaku untuk informasi yang tidak dapat diproses atau dianalisis menggunakan alat tradisional. 
Menurut [9] , Big data adalah data yang melebihi proses kapasitas dari kovensi sistem database yang ada. Data terlalu besar dan terlalu cepat atau tidak sesuai dengan struktur arsitektur database yang ada. Untuk mendapatkan nilai dari data, maka harus memilih jalan altenatif untuk memprosesnya.

Penggunaan Big data dalam melakukan survey penjualan Real estate di negara china.penelitiannya menjelaskan keuntungan dan kekuatannnya dalam melakukan penjualan real estate dengan menggunakan aplikasi teknologi Big data [10]. Menjelaskan [11] peranan Big data dalam menganalisis dan mengembangkan data e-goverment untuk melakukan perubahan sehingga lebih efektif dan efesien dalam memberikan pelayanan. Penggunaan Big data untuk menciptakan kota pintar, yang memberikan berbagai service ilmu pengetahuan dalam menyimpan data yang begitu besar sehingga dapat memberikan informasi dari berbagai service dalam sebuah kota [12]. Menjelasakan [13] analisa Big data untuk kunjungan tourism yang berasal dari negra sweden. Dalam penelitian ini dibahas manfaat analisa daera wisata dapat dengan cepat dan jelas kelebihan dan keuntungan dari masyarakat yang akan berkunjung ke daerah tersebut. Menjelaskan [14] teknologi Big data dalam pendekatan pencegahan penyebaran penyakit HIV dengan menggunakan teknologi digital seperti handphone.

\subsection{Visualisasi Data}

Analis dapat menerapkan pengolahan data secara realtime dengan cara memvisualisasikan hasil dari pengolahan data [15]. Dalam melakukan visualisasi data untuk mengoptimalkan permasalahan di ilmu komputer khususnya dibidang akademik penulis menggunakan Tableau. Arsitektur Tableau dalam melakukan visualisasi data dapat dilihat pada gambar 2 dibawah ini :

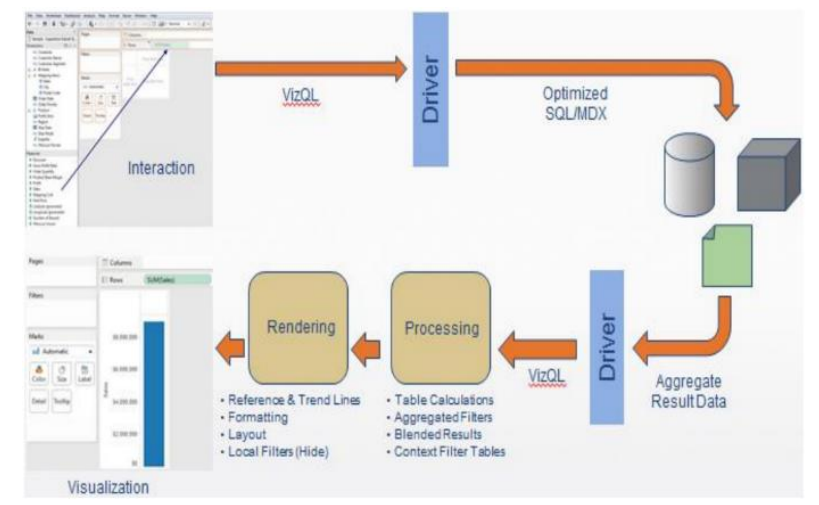

Gambar 2. Aristektur Pengolahan data Tableau [16]

Pada tahun 2003 Tableau berasal dari Stanford University dengan VizQL ${ }^{\mathrm{TM}}$, sebuah teknologi yang benar-benar melakukan perubahan yang bekerja dengan data dengan memungkinkan sederhana drag dan drop fungsi untuk membuat visualisasi yang canggih. Inovasi yang mendasar adalah bahasa dipatenkan query yang diterjemahkan tindakan ke query database kemudian menyampaikan tanggapan grafis. Terobosan berikutnya adalah kemampuan untuk melakukan analisis pada jutaan baris data dalam detik dengan Mesin Data Tableau [16]. Tableau adalah sistem komersial, berdasarkan Polaris [17] untuk memvisualisasikan isi dari database. Antarmuka Tableau mencakup daftar bidang database tersedia dan ruang 
kerja di mana pengguna dapat memilih bidang dan menyeret mereka ke rak-rak yang sesuai untuk pengkodean visual seperti posisi, warna, bentuk dan ukuran. Tablo didasarkan pada spesifikasi bahasa disebut VizQL. VizQL pernyataan yang dihasilkan dari isi rak antarmuka dan mereka menentukan data yang harus divisualisasikan (sebagai perintah query database) dan bagaimana visualisasi akan muncul (sebagai pernyataan spesifikasi visual). Pengolahan data Tableau mendukung berbagai visualisasi, termasuk bar charts, time series, scatter plots, and heat maps, serta analisis operasi seperti penyaringan, penyortiran, dan pencarian [17].

Mirip dengan Microsoft Excel, Tableau mendukung beberapa lembar kerja. Masing-masing worksheet Tableau digambarkan oleh pernyataan VizQL [18]. Dalam melakukan visualisasi data tahapan yang dilakukan :

1. Melakukan koneksi dengan database SQL server yang berjalan secara real time.

2. Menyiapkan tiga workshet yang terdiri dari worksheet :
a. Jumlah mahasiswa
b. Status mahasiswa
c. Nama mahasiswa

3. Mendesign dashboard dari worksheet yang telah dibuat. Dalam visualisasikan data di dashboard menggunakan action yang menghubungkan dari semua worksheet.

A. Worksheet Jumlah mahasiswa

Dalam membuat worksheet mahasiswa, jumlah mahasiswa di visualisasikan berdasarkan tahun masuk yang di filter berdasarkan tahun masuk dan status mahasiswa. Jumlah mahasiswa kita menggunakan chart circle, seperti gambar 3 dibawah ini :

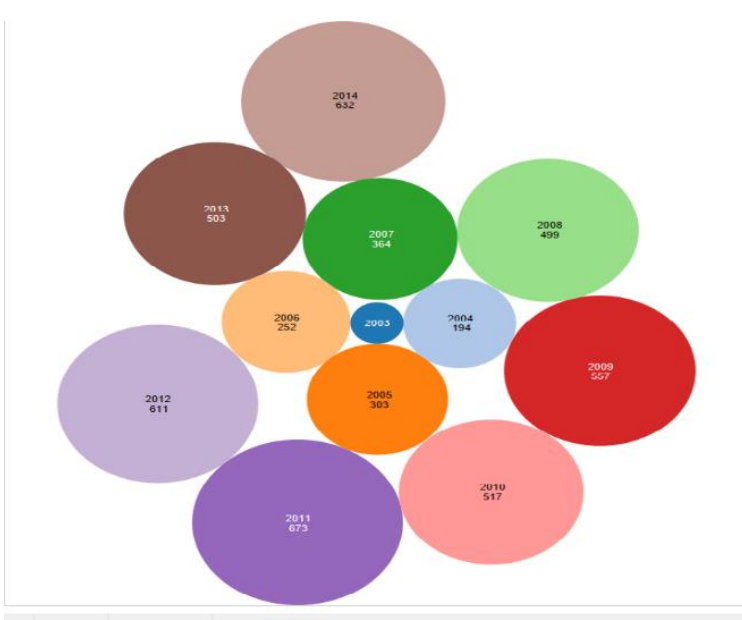

Gambar 3. worksheet jumlah mahasiswa

\section{B. Worksheet status mahasiswa}

Dalam membuat worksheet status mahasiswa, status mahasiswa di visualisasikan berdasarkan nama kelas dengan jumlah mahasiswa yang berada dikelas tersebut. Filter dan warna berdasarkan tahun masuk dan status mahasiswa. Nama kelas kita menggunakan Stacked Bars, seperti gambar 4 dibawah ini : 


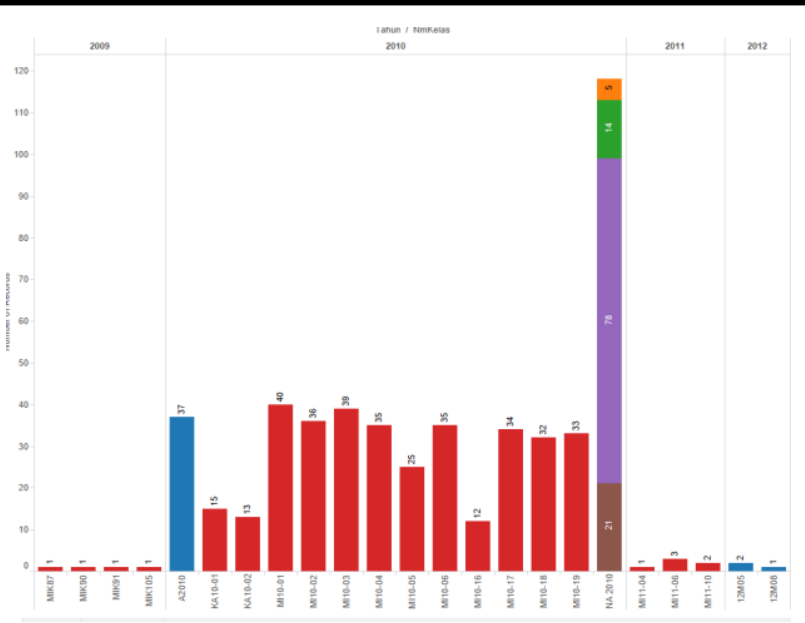

Gambar 4. worksheet status mahasiswa

C. Worksheet nama mahasiswa

Dalam membuat worksheet nama mahasiswa, status nama mahasiswa di visualisasikan berdasarkan nim, nama, nama kelas, sesi dan status. Filter berdasarkan tahun masuk dan status mahasiswa. Data mahasiswa menggunakan table sheet, seperti gambar 5 dibawah ini :

\begin{tabular}{|c|c|c|c|c|}
\hline NIM & Nama & NmKelas & Sesi & \\
\hline 201001030001 & AGUS ANWARI L. TOBING & NA 2010 & Pagi & Transfer \\
\hline 201001030002 & ALMOSEN MANOGI GRAZIO.. & MI10-01 & Pagi & Lulus \\
\hline 201001030003 & BENNY HARDANI HUTAPEA & MI10-01 & Pagi & Lulus \\
\hline 201001030004 & DEWI MUSTIKA SARI & MI10-03 & Pagi & Lulus \\
\hline 201001030005 & ELLA SRIWAHYUNI & MI10-01 & Pagi & Lulus \\
\hline 201001030006 & FAJAR FADILAH & MI10-01 & Pagi & Lulus \\
\hline 201001030007 & GUSTIA NINGSIH BATUBARA & MI10-03 & Pagi & Lulus \\
\hline 201001030008 & HENI VERAWATI & MI10-03 & Pagi & Lulus \\
\hline 201001030009 & INDRA PUTRI BUDIASIH RA.. & NA 2010 & Pagi & Transfer \\
\hline 201001030010 & JOKO SANTOSO & MI10-01 & Pagi & Lulus \\
\hline 201001030011 & LILIS CIPTAMI SUYANTI SIA... & MI10-03 & Pagi & Lulus \\
\hline 201001030012 & OKKY PUTRA ARIYANA & MI10-01 & Pagi & Lulus \\
\hline 201001030013 & PRAYETNO & MI10-01 & Pagi & Lulus \\
\hline 201001030014 & RIO SANJAYA DAMANIK & MI10-01 & Pagi & Lulus \\
\hline 201001030015 & RIYAN TANTOWI & MI10-01 & Pagi & Lulus \\
\hline 201001030016 & SEHAN PARSETIA & MI10-01 & Pagi & Lulus \\
\hline 201001030017 & SRI MAULIDA PURWANING.. & MI10-03 & Pagi & Lulus \\
\hline 201001030018 & TRI VELLA YATI & NA 2010 & Pagi & Non Aktif \\
\hline 201001030019 & WIWIK LESTARI & MI10-03 & Pagi & Lulus \\
\hline 201001030020 & YULIA CITRA DEWI & A2010 & Pagi & Aktif \\
\hline 201001030021 & ANDRIANSYAH RUKMAN & MI10-01 & Pagi & Lulus \\
\hline 201001030022 & ARFYAH YUSLINA & MI10-01 & Pagi & Lulus \\
\hline 201001030023 & AS'AD PRANATA & NA 2010 & Pagi & Non $A$ \\
\hline 201001030024 & DEAH PRAMANA & NA 2010 & Pagi & Non Aktif \\
\hline
\end{tabular}

Gambar 5. Worksheet nama mahasiswa

\subsection{Analisis Visualisasi}

Untuk mendapatkan hasil dari gabungan bebarapa worksheet, langkah selanjutnya agar lembar kerja bekerja secara optimal terhadap data yang digunakan langkah selanjutnya memindahkan semua worksheet kedalam dashboard. Sebuah dashboard adalah kumpulan dari beberapa lembar kerja dan informasi pendukung yang ditampilkan dalam satu tempat sehingga dapat membandingkan dan memantau berbagai data secara bersamaan. Misalnya, kita memiliki satu set pandangan bahwa analisis data diperiksa setiap hari. Daripada membalik setiap lembar, kita dapat membuat sebuah dashboard yang menampilkan semua pandangan sekaligus. Setiap tampilan yang di tambahkan ke dashboard terhubung ke lembar kerja yang sesuai. Bahwa berarti bila mengubah worksheet, dashboard 
diperbarui dan ketika mengubah tampilan di dashboard, worksheet diperbarui [16], seperti pada gambar 6 di bawah ini.

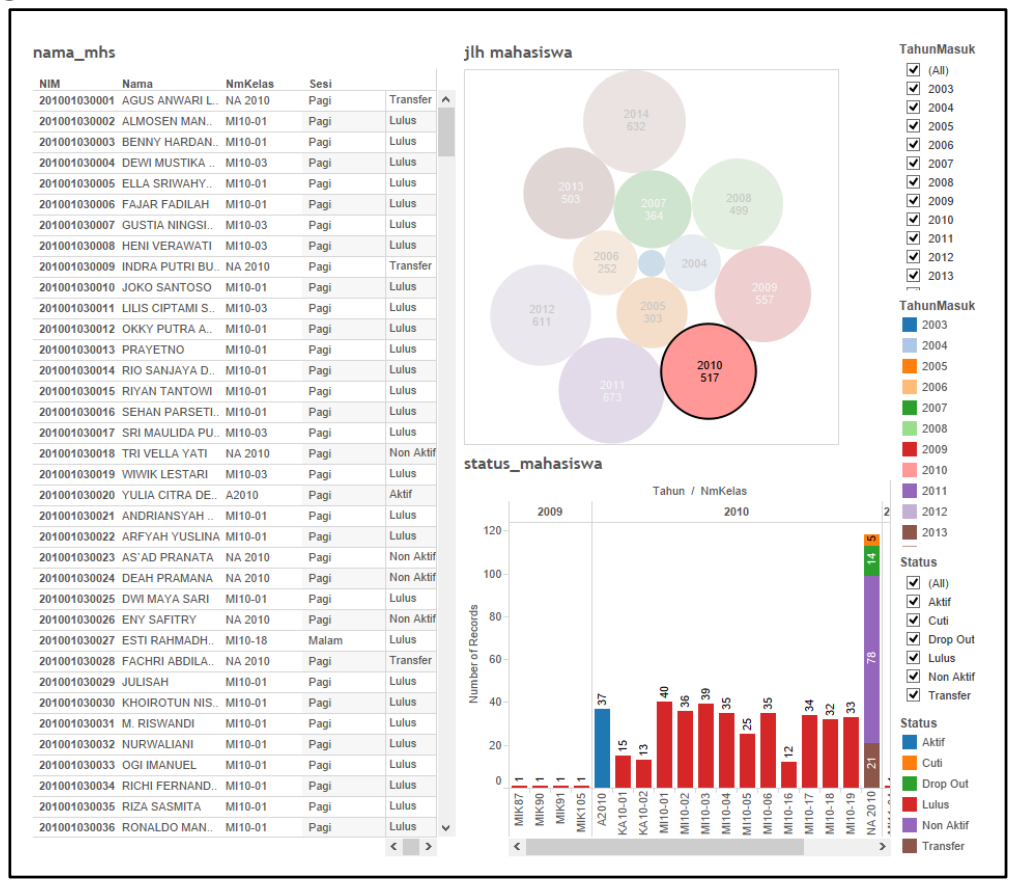

Gambar 6. Dashboard data mahasiswa

Dengan adanya dashboard dan dapat dibaca oleh Tableau reader maka manajemen dapat dengan cepat mengetahui jumlah mahasiswa perangkatan, status mahasiswa berdasarkan aktif, cuti, lulus, non aktif, transfer dan drop out. Manajemen juga dapat dengan cepat nim, nama sesi dan status dari data akademik dari nim dan nama mahasiswa sebagai kunci primary key seperti pada gambar 7 dibawah ini

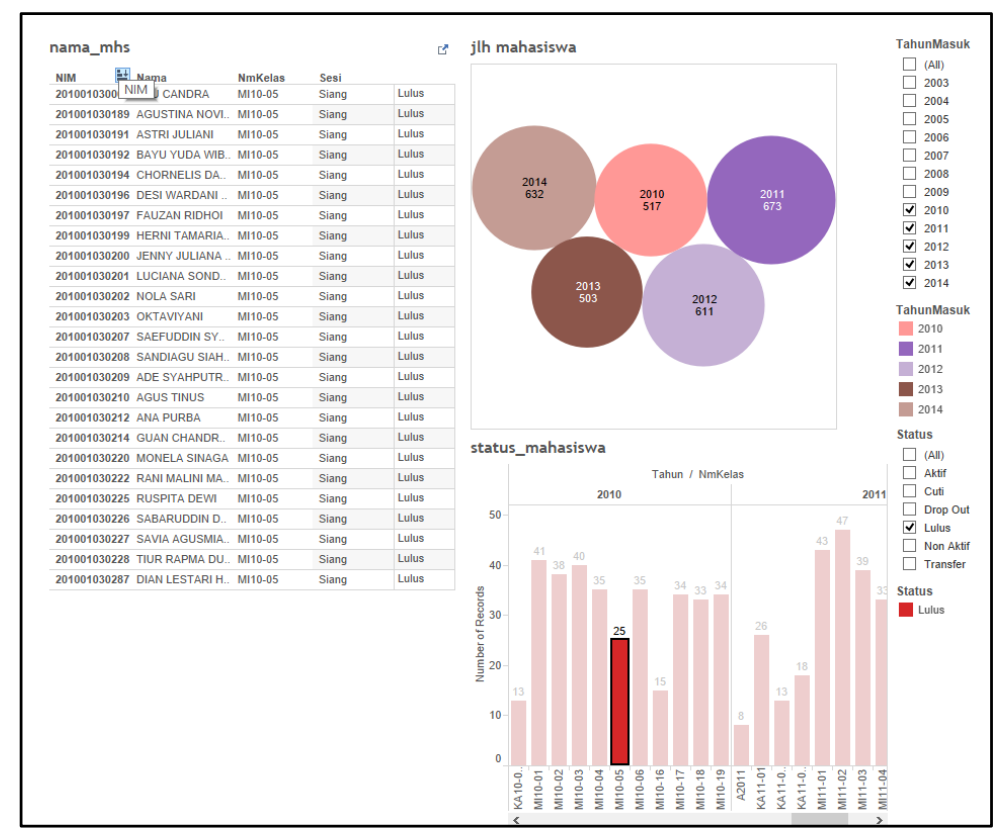

Gambar 7. Dashboard data mahasiswa lulus 
Dashboard pada gambar 7 diatas dapat menampilkan dengan cepat data mahasiswa lima tahun terakhir yang sudah lulus dengan menampilkan nama mahasiswa di table sheet nama mahasiswa. Cara kerja menampilkan diatas adalah :

1. Berikan check list lima tahun terakhir dari tahun 2014 sampai dengan 2010 di worksheet jlh mahasiswa.

2. Pilih status lulus di worksheet status mahasiswa.

3. Pilih grafik bar yang menunjukan jumlah mahasiswa di kelas tersebut yang telah lulus dan akan menampilkan nim, nama mahasiswa secara lengkap dan cepat seperti pada gambar dibawah ini

\section{SIMPULAN}

Kesimpulan yang dapat ditarik dari studi ini adalah :

1. Visualisasi dalam bentuk laporan grafik dapat mengoptimalkan permasalahan dalam manajemen pendidikan.

2. Permasalahan dalam ilmu komputer dengan teknologi Big data dapat dengan cepat menghasilkan analisis yang memberikan pengetahuan baru terhadap Big data.

3. Arsitektur Tableau dapat menyelesaikan dan mengoptimalakan permasalahan data yang besar dalam lingkungan manajemen bisnis.

\section{DAFTAR PUSTAKA}

[1] S. Kaisler, F. Amoour, J. a. Espinosa dan W. Money, "Big data : Issues and Chalenges Moving Forward," Hawaii International Conference on System Sciences, vol. 46 th, pp. 995-999, 2013.

[2] 4syth.com, "For Big data Analytics There's No Such Thing as Too Big The Compelling Economics and Technology of Big data Computing," Emerging Big data thought White Paper, March 2012.

[3] ULARU, E. Geanina, PUICAN, F. Camelia, A. Anca dan V. Manole, "Perspectives on Big dataand Big data Analytics," Database Systems Journal, vol. III, no. 4, pp. 3-13, 2014.

[4] N. Sibley, Using Tableau for Visual Analytics in Libraries, Simmons Colleg, 2013.

[5] S. A. Murphy, "Data Visualization and Rapid Analytics: Applying Tableau Desktop to Support Library Decision-Making," Journal of Web Librarianship, no. 7:4, pp. 465-476, 2013.

[6] Zhao, D. W. Tian dan D. Yong, Optimized Cloud Resource Management and Scheduling, Elsevier Inc, 2015.

[7] R. Ranjan, "Modeling and Simulation in Performance Optimization of Big data Processing Frameworks," dalam I E E E Cloud Computing, I E E E Computer Society, 2014, pp. 76-81.

[8] C. Eaton, D. Dirk, D. Tom, L. George dan Z. Paul, Understanding Big data, Mc Graw Hill.

[9] E. Dumbill, Big data Now Current Perspective, O'Reilly Media, 2012.

[10] D. Du, A. li dan L. Z, “'Survey on the Application Of Big data in Chinese real Estate Enterprise”,", International Conference on data Science ICDS, pp. 24-33, 2014.

[11] A. J. R. C dan N. Jhonson, "Big data and Transformational Goverment," IEEE, 2013.

[12] F. D. C. a.Xhafa, "Intellegent Services For Big data Science," Future Generation Computer system, pp. 198-209, 2014.

[13] F. M, H. W dan L. M, "Big data Analytics For Knowledge Generation in Tourism Destination A case from Sweden," Journal of Destination Marketing and Management, pp. 198-209, 2014. 
[14] Y. S. D, "A Big data approach to HIV epidemiology and preventation," Preventive Medicine, pp. $17-18,2015$.

[15] S. Kandel, A. Paepcke, J. M. Hellerstein dan a. J. Heer, "Enterprise Data Analysis and Visualization: An Interview Study," IEEE Transactions On Visualization And Computer Graphics, vol. 18, no. 12, pp. 2917-2926, 2012.

[16] C. T. Center, "Tableau Desktop Fundamental," dalam Tableau Classroom Training, Jakarta, Cybertrend Training Center , 2015.

[17] S. C., T. D. dan H. P. Polaris, "A System for Query, Analysis,," IEEE Trans. on Visualization and Comp. Graphics and Visualization of Multidimensional Relational Databases, vol. 8, no. 1, pp. 5265, 2002.

[18] J. Heer, J. D. Mackinlay, C. Stolte dan a. M. Agrawala, "Graphical Histories for Visualization: Supporting Analysis, Communication, and Evaluation," IEEE Transactions On Visualization And Computer Graphics, vol. 14, no. 6, pp. 1189-1996, 2008. 